education or training, and it includes the power to convey. But crucially, it fails to give the power to require patients to receive treatment against their will as part of their supervised discharge.

The administrative changes which the government has introduced such as the supervision register and the new Bill are intended to respond to the fact of increasing numbers of psychiatric patients who now live in the community but who may pose a risk to themselves or others if they were to default from supervised care which by definition includes the receipt of psychotropic medication. The question is whether these administrative changes are appropriate in the circumstances or indeed, whether they can be deemed to be ethically justifiable.

It seems perverse that patients can be legally required to attend for occupation, education or training, yet cannot be required to accept what is clearly the single most important factor in sustaining their wellbeing, namely medication. If particular individuals are at such a risk to themselves or others that their names can be put on a supervision register, and furthermore can be obliged by law to observe certain requirements, thus depriving them of their autonomy, it seems illogical to grant such powers for relatively trivial matters such as occupation, education and training but to deny powers of this kind for important matters such as medical treatment.

This new Bill underlines society's reluctance to acknowledge properly the need for a fundmental change in how it legislates for the treatment of psychiatric patients in the light of the new disposition of psychiatric services. We believe that a community treatment order, in one form or the other, with the appropriate safeguards, is what is required.

HMSO (1995) Mental Health (Patients in the Community) Bill.

FEMI OYEBODE and MOHAN GEORGE, South Birmingham Mental NHS Trust, The Queen Elizabeth Psychiatric Hospital, Edgbaston, Birmingham B15 $2 \mathrm{QZ}$

\section{Detention under the Mental Health Act}

Sir: Detention under the Mental Health Act is a serious business and the impartial system provided by Hospital Managers Meetings and Mental Health Review Tribunals is clearly needed to prevent abuses. It was not, however, without some sympathy that I read Dr Hambridge's letter (Psychiatric Bulletin. April 1995, 19, 258).

A disturbed and dangerous 19-year-old man suffering from schizo-affective psychosis was detained under section 3 of the Mental Health Act 1983 in September 1994. During his detention the patient has had three hearings by hospital managers in September, November and a Renewal Hearing (section 30) in March. On each occasion the detention under the Mental Health Act was upheld. In addition, three Mental Health Review Tribunals have been arranged. The first tribunal met in December 1994 and as adjourned (against my advice) because the patient was deemed by the tribunal too unfit (he was suffering from a minor urinary tract infection). The tribunal was rescheduled for later that month but the patient withdrew his application on the day of the hearing. Eventually the tribunal was held in March 1995 and upheld detention. On each occasion, apart from the costs of the Hearing Panel, clinical work has been cancelled by myself, team social worker and ward manager. Time and money has been expended on solicitors, second opinion doctors, medical records staff and secretarial time.

The hearings have been held in a wholly professional and dignified way but represent a stress for all concerned. If professionals find these meetings stressful what is the effect on our patients? It is sad that a person in a disturbed and insightless state is allowed to subject himself to such a recurrent nontherapeutic experience when parents, the professionals involved and even solicitor acting on his behalf were convinced of the necessity for him to remain detained under the Mental Health Act.

The patient has now applied for another Mental Health Review Tribunal (his seventh hearing); I am pleased however to report that he has improved sufficiently now to be regraded to informal status.

I. J. McLoughuIN, East Gloucestershire NHS Trust, The Chareton Lane Centre, Cheltenham GL53 9DZ

\section{Patients taping staff}

Sir: The article by Matthew Stephenson regarding patients taping staff (Psychiatric Bulletin, 1995, 19, 252-253) raises valid points about the potential for appropriate use 